\title{
Intellectual Property Rights: The Effects on Information Security and Research Innovations in Nigeria
}

\author{
Felix. C. Aguboshim ${ }^{1}$ and Irene. N. Ezeasomba ${ }^{2}$ \\ Principal Lecturer, Department of Computer Science, Federal Polytechnic, Oko Nigeria. \\ ${ }^{1}$ felixaguboshim@gmail.com; +2348037109290 \\ 2ezeasombairene@gmail.com; +2348033970110
}

\begin{abstract}
The rise of new digital technologies and file-sharing networks has definitely made it harder for organizations to protect their intellectual property (IP). This is made even harder by the fact that there is no uniformity in the enforcement of laws that are designed to protect against IP theft, especially in Nigeria. Nigeria is ranked among countries in Africa where Intellectual Property (IP) theft or piracy is prevalent. Technology required for the operation of Intellectual Property Rights (IPRs) in Nigeria is still largely undeveloped,out-dated, and nonsustainable despite the huge human resources and technological innovations. This study highlights the gaps created by the ineffectiveness of anti-counterfeiting and anti-piracy tactics to curb the challenges of IP and strategies to close them. In this study, the authors explored a narrative review of prior research that focused on the theoretical underpinnings of vast works of literature that revealed significant information on IP challenges facing research and innovation for national development and strategies to close these gaps. The authors also extracted peerreviewed articles within the last five years from electronic databases, using some keywords such as "intellectual property", "IPRs", "IP penalty and offences", etc. Results show that IP regulations and policies are crippled by out-dated, non-sustainable or virtually non-existent policies, counterfeiting and anti-piracy system. Findings from this study may encourage proper implementation of IP: copyrights, trademarks, patents, and trade secrets for technological innovations and development in Nigeria.
\end{abstract}

Keyword:Intellectual property copyrights. Trademarks, Trade secrets, Intellectual property, ICT sustainability|

DOI: $10.7176 / \mathrm{ISDE} / 10-7-06$

Publication date: October $31^{\text {st }} 2019$

\section{Introduction}

Intellectual property rights (IPR) in research innovations can be defined as the right to assign the research results to its creator, not limited to time and space, and non-transferable (Sargolzaei \& Fateme, 2017). World Intellectual Property Organization (WIPO, n. d., as cited in Blakeney, 2005) stated that intellectual property may include the rights relating to:literary, artistic and scientific works;performances of performing artists, phonograms, and broadcasts;inventions and innovations; scientific discoveries; industrial designs; trademarks, service marks, and commercial names and designations;protection against unfair competition; andall other rights resulting from intellectual activity in the industrial, scientific, literary or artistic fields.In research innovations, two points of view can be considered for copyrights: (a) as incentives for creative production, and (b) as a commodity for the consumer, who seeks to use it for free or at a negligible cost. While developed countries are struggling to secure the first view, the developing countries attempt to reach a second view to have access to the copyright easier and at a lower cost. According to the International Telecommunication Union (ITU), intellectual property rights arelegal rights designed to protect creations and/or inventions resulting from intellectual activity in education, industrial, scientific, literary, or artistic fields (ITU, 2017). Intellectual property rights usually give thecreator exclusive use of their creation for a specified period of time.

In relation to IPR, information security has been defined from a multiple perspectives (Narain, Gupta, \& Ojha, 2014), and with a holistic approach that expands beyond the technical security (Perez, Branch, \& Kuofie, 2014), to comprise the environment, the technology, and the people (Stallings \& Brown, 2012; Taylor \& Robinson, 2015). Significant amount of empirical researches point to the fact that humans appear to be the most important links to the information security of any organization, and invariably constitute the highest risk to the information security measures and information integrity of any organization (Stallings \& Brown, 2012). This is because of the differences in behavior regarding the intent to implement security measures or administrative errors (Komatsu, Takagi, \& Takemura, 2013).Information security defined the technique by which innovational institutions protect and secure systems and system resources, media, and facilities that process and maintains information. Key 
elements of any security program must address: confidentiality,integrity, and availability (Stallings \& Brown, 2012).

Information security within the IPR has never been more important than it is today: not only in how it can protect andencourage research innovations bygranting successful inventors temporary monopoly power over their innovations data or systems, but how it can enhance secure information exchange between trusted partners.Universities and public research institutions through research innovations are the factories of the knowledge, economy growth, and job creation (Blakeney \&Mengistie, 2011). This is because Innovation drives economic growth and job creation. The International Property Rights Index assumes a significant correlation between the protection of private property rights and a nation's innovations and economic growth (Blakeney \& Mengistie, 2011).

It has also been observed that there is a significant causal relationship between intellectual property (IP), technology transfer and development(Neba, 2013).Therefore, protection of intellectual property (IP), through patents, trademarks and copyrights, is critical to ensuring pursuit of innovation, economic growth, and technology transfer and job creation. Intellectual property rights are therefore the changing face of research innovations. As a critical component of national innovation systems, IPR systems are expected to play a catalytic role in encouraging innovation and successful technology transfer from research and higher education institutions. However, building capacity for IP policy formulation (in general) includes building institutional (university/research institute) capacity, as well building capacity for IP policy formulation among government officials are farfetched. This is because technological capabilities are now more widely diffused and production more globalized, and concerns relating to inadequate enforcement of IP rights, in particular patents and trademarks, have increased.

As a result, information security and research innovations, especially in tertiary education in Nigeria, are tremendously challenged due to inadequate enforcement of IPRs, inadequate awareness about copyright piracy and its ills. Researchers and innovators, especially in education,find it difficult, if not impossible, to attain their ultimate goals or create added value through their work, knowledge, and ideas. This study highlights the gaps created by this ineffectiveness of anti-counterfeiting and anti-piracy tactics to curb the challenges of IP and strategies to close them.IPRs encourage researchers to engage in innovative activities by protecting their knowledge and open access to knowledge and technologies contributing to sustainable development. IP systems are designed to develop and implement environment in which creativity and innovation can effectively trive. The general idea is that IPR will give incentive toresearchers and investors to devote time, effort, and money to work oninnovations and then share their ideas with society. In return, creators get amonopoly or some other form of protection for their idea for a limited timespan. The purpose is to maximize economic growth while balancing the socialcosts to a manageable level, and at the same time build a pool ofknowledge and ideas that other researchers and scientist can make use of totake greater and faster strides in innovation.

\section{Literature Review}

Intellectual Property (IP) according to Blakeney (2005), can be defined as those creations of the mind in relation to which the state or country confers upon individuals a statutory monopoly for a prescribed term to prevent their unauthorized exploitation. Intellectual property is usually divided into two branches: industrial property and copyright and the rights which neighbor upon copyright. Piquero (2005) simple defines intellectual Property (IP) as the creative ideas or innovations that result from intellectual activity and creation. Nigeria is ranked among countries in Africa where Intellectual Property (IP) theft or piracy is prevalent. It was $82 \%$ in $2007,83 \%$ in 2008 , $83 \%$ in $2009,82 \%$ in 2010 and $82 \%$ in 2011 (Business Software Alliance, 2011). According to the report, IP theft or piracy also blossoms in other African countries, including Zimbabwe (92\%), Libya (90\%), Algeria (84\%), Cameroon (83\%), Egypt (61\%), Ivory Coast (81\%), Kenya (78\%), Mauritius (57\%), Morocco (66\%), Senegal (78\%), Tunisia (74\%), Zambia (82\%); while South Africa (35\%) had the least piracy rate (Business Software Alliance, 2011; Nwokocha, 2012 ).

Theft or Piracy in this context include among others, IP distributed without authority, packaged to resemble the original as closely as possible; or copied or distributed without authority (Adedej, 2011a). In Nigeria, causes and motivations for Intellectual Property theft or piracy are myriad (Adewopo, 2008). Some of these causes include no concerted effort of established bodies like Nigerian Copyright Commission, scarcity and high cost of genuine products, abuse of digital technology, inadequate enforcement of intellectual property laws, culture, poverty, laziness, inadequate awareness about copyright piracy and its ills, poor distribution networks of needed creative products, slow judicial system, poor funding of regulatory agencies and rancorous and uncooperative attitude of practitioners in the creative industries.Other serious challenges include the simple fact that a lot of people in Nigeria were unaware of IPRs and implications of IP theft. The concept until recently was foreign such 
that individuals and organizations alike did not appreciate that they could commercially exploit their IPRs or that IPRs are assets of immense value. Also there were very few IP Practitioners in Nigeria and those practitioners had a difficult time convincing the Courts to enforce IPRs. There was no respect for IP. Most importantly IT availability, operations, and standards with appropriate databases required to enforce IPRs is next to zero in Nigeria.

Nevertheless, the Nigerian Copyrights Commission (NCC) sees illegal exploitation of copyright works as crime (Tade, \& Akinleye, 2012). The Nigerian Copyright Commission, was launched as a Countermeasures to IP piracy. It deploys three basic intervention components: public enlightenment, proactive enforcement and the administration of rights (Adedej, 2011b). Other bodies include the National Office for Technology Acquisition and Transfer registers Technical Service Agreements and Technology Transfer and Know How Agreements, Intellectual Property Lawyers Association of Nigeria (IPLAN), Nigerian Local Chapter of the International Association for the Protection of Intellectual Property (AIPPI) and Anti-Counterfeiting Collaboration (ACC), Nigeria. Others are the Nigerian Intellectual Property Commission (NIPCOM) Bill which is currently waiting enactments largely due to efforts of the IP community, both private and public working together with the various international associations.

The faculties of law of Nigerian Universities now offer courses in IP. The Performing Musicians Association of Nigeria (PMAN) and Federation of Intellectual Property Owners (FIPO) both play significant roles in protecting members' rights as well as Collective Management Organization (CMO). Other IP-related regulatory agencies such as NAFDAC, SON, TM Registry, NBC, and NFVCB are merely trying to make or enforcement reasonable impact on IPRs and IPR related issues. One of the major IPR challenged to be tackled is that of providing adequate skills and competent manpower for the administration of IPRs. Persons concerned in its administration area or unit are sometimes not consultants. Again the infrastructure like Information Technology required for the operation of IPR in Nigeria is still largely undeveloped (Nwokocha, 2012). The penalty for offence of IPRs is not sufficient to deter would-be offenders. The only remedy for an owner in a civil action in court, leaving except in the area of copyright where the owner can institute a criminal action thorough the Nigerian Copyright Commission (NCC).

\subsection{Enablers of IPRs.}

Two major enablers of IPRs are sustainable information and communication technology (ICT), and sustainable research database repository. ICT can be simply defined as the physical devices and infrastructures used for the collection, storage, processing, and disseminating of all forms and formats of data and information, and the required platforms or means for the transmission and disseminating of same (Oladimeji \& Foltyn, 2018; Olise, 2010 ). Sustainable ICT is what defines sustainable research database repository (Aguboshim, Ezeasomba, \& Ezeife, 2019; Oladimeji\& Foltyn, 2018), and occupies a significant key position in leveraging sustainable IPRs (Olise, 2010). A significant relationship exists between sustainable ICT and sustainable research database repository (Bennett, 2017). Also, Sustainable ICT operations, and standards with appropriate databases are required to enforce IPRs.

A significant relationship exists between sustainable ICT and sustainable research database repository (Aguboshim, et al., 2019; Bennett, 2017). Also, Sustainable ICT operations, and standards with appropriate databases are required to enforce IPRs. A country's optimal IPRs is a function of its level of technological development, adoption and sustainability (Chen\&Puttitanun, 2005; Hoffman, Singh, \& Prakash, 2015). Where Sustainable ICT, availability, operations, and standards with appropriate databases required to empower sustainable research database repository, are not in place, sustainable IPRs will be farfetched. This is why effective IPRs is next to zero in Nigeria because ICT technological innovations, as enablers of sustainable research database repositoryand IPpolicies are not respectfully adopted. The value placed on any technological innovation is measured by its adoption, acceptance, and sustainability (Hoffman, et al., 2015). Sustainable ICT, therefore, plays an important role in sustainable research database repository and IPRs implementation(Oladimeji \& Foltyn, 2018). This is because ICT is a major enabler of sustainable research database repository and IPRs (Toyo \& Ejedafiru, 2016).

\section{Methodology}

A narrative review methodology is adopted where analysis and synthesis of different and related research findings are required to draw holistic interpretations or conclusions based on the reviewers' own experience, existing theories and models (Hill \&Burrows, 2017).In this study, we adopted a narrative review approach. We also reviewed, analyzed and synthesized prior research findings. A narrative study approach is best suited for a 
descriptive or explanatory study (Bell, 2017), where results from such narrative studies are of qualitative rather than quantitative in nature (Scarnato, 2017). Narrative studies exhibit significant strengths in that they have ability to provide platforms for comprehension of diverse and numerous understanding around scholarly research findings, and the opportunity to make reflective practice and acknowledgement of researchers' views and knowledge (Scarnato, 2017). Methodological triangulation has been defined as the use of multiple sources of data to gain multiple perspectives, maximize reliability and validation of data and build coherent justification of data interpretation that relates to the study case or phenomenon (Durif-Bruckert, et al., 2014). We adopted methodological triangulation to ensure the reliability and validity of data, and justification of interpretations from the reviews.

\section{Data Collection}

Professional and academic research findings that are relevant and related to our study were reviewed. Many of such findings came from the ProQuest databases, ScienceDirect, Walden University international library databases and peer-reviewed, and other related texts. We also used phrases as such as "intellectual property", "IPRs", "IP penalty and offences", etc., and terms as key search words in the databases for related literature. Our reviews incorporated 30 references. Twenty six $(87 \%)$ of total references incorporated in the study are peer-reviewed, while $(55 \%)$ are peer-reviewed journals that are within the last 5 years.

\section{Findings}

Creating patent and copyright monopolies, as well as otherforms of intellectual property, justifies the ability to appropriate the returnsto innovative activities granted by these monopolies, without which the market wouldundersupply research, innovation, and creative work. Granting a monopoly for a limited period of time in the form of a copyright is therefore one solution. Research is incentivized, but at the cost of inefficiency in the current usage of knowledge. There is a static/ dynamic trade-off. Findings have shown that a country's optimal IPRs depend on its level of technological development, adoption and sustainability in anon-monotonic way, first decreasing and then increasing (Stewart \& Lacey, 2012). According to Chen and Puttitanun(2005), lower IPRs encourageimitations or theft of foreign technologies, which reduces the market power of foreign innovations and benefits domestic consumers. On the other hand, a developing country may also need to increaseIPRs in order to encourage innovations by domestic consumers (Chen\&Puttitanun, 2005).It was noted that innovation ina developing country increases with the protection of IPRs. Findings confirmed an empirical evidence of both the positive impact of IPRson innovations in developing countries and the presence of a U-shaped relationship between IPRs and information security and research innovations for economic development.

\section{Conclusion and Recommendations}

A country's optimal IPRs depend on its level of technological development and sustainability. Intellectual Property Rights (IPRs) are worth protecting because of their significant importance in leveraging sustainable growth of research innovations. IPRs are a double-edged sword. This is because while the motivation for intellectual property is to provide incentives for research on new technologies, intellectual property also affects incentives for research on subsequent applications and improvements on the initial discovery. Therefore IPRs may both impact research innovations highly or lowly depending how on the level of increase of the protective IPRs. As a developing Country, Nigeria may have to increase IPRs in order to encourage innovations by domestic consumers. IPRs are there to make innovators' rights clear and known to them, and to competitors to discourage infringement, innovators' intellectual property should be traceable but difficult to others to infringe. Nigeria should develop an indigenous law that will address basic issues on IPRs that will positively address its economy and social cultural environment. The tight restrictions that digital content owners place on their products encouraged even more pirating and plagiarism. Reid (2012) explains that as the industry played hardball with violators, people became more adapt at illegally distributing IP content, and are morally comfortable with them, in the absence of any legal alternative. In essence, the legal prosecution backfired and started more illicit distribution of protected material. Therefore, the most effective method for copyright holders to use in protecting their property is by offering it at competitive rates through distributors like Amazon, Apple, national and international journal bodies or other on line services. 


\section{References}

Adedej, A. (2011a). Combating piracy through optical Disc plant regulation inNigeria: Prospects and challenges. Journal of Intellectual Property [NJIP] Maiden Edition (2011)

Adedej,A. (2011b). The Strategic Action Against Piracy (STRAP) Policy in Nigeria,Research Papers from the WIPO-WTO Colloquium for Teachers of Intellectual Property Law 2010. (Geneva: WIPO-WTO, 2011), 107118.

Adewopo, A. A. (2008). The Gain is More than the Pain: Cost Benefit Perspective ofthe Regulation and Control of Copyright Based Industries in Nigeria?.International symposium on economic crimes. Jesus College University of Cambridge United Kingdom. p.6http://www.nials-nigeria.org/journals/Wole\%20Adedejinjip.pdf

Aguboshim, F. C., Ezeasomba, I. N., \& Ezeife, J. E. (2019). Sustainable Information and Communication Technology (ICT) for Sustainable Data Governance in Nigeria: A Narrative Review. Journal of Information Engineering and Application (JIEA), 9(5), 15-20. doi:10.7176/jiea/9-5-02

Bell, E. E. (2017). A Narrative Inquiry: A Black Male Looking to Teach. The Qualitative Report, 22(4), $1137-$ 1150.

Bennett, S. (2017). What is information governance and how does it differ from data governance? Governance Directions, 69(8), 462-467.

Blakeney, M. (2005). Guidebook On Enforcement Of Intellectual Property Rights.Queen Mary Intellectual Property Research Institute Queen Mary, University of London.Retrieved from: http://trade.ec.europa.eu/doclib/docs/ 2005/ april/tradoc_122641.pdf

Blakeney, M., \& Mengistie, G. (2011). Intellectual Property and Economic Development in sub-Saharan Africa. Journal of World Intellectual Property 14(3/4): 238-264. doi: 10.111/j.1747-1796-00417.x

Business Software Alliance (2011). Shadow Market. In 2011 Global software piracystudy. Ninth Edition, May, 2012

Chen, Y., \& Puttitanun, P. (2005).Intellectual Property Rights and Innovation in Developing Countries.Journal of Development Economics, 78(1), 474-493. doi:10.1016/j.jdeveco.2004.11.005

Durif-Bruckert, C., Roux, P., Morelle, M., Mignotte, H., Faure, C., \& Moumjid-Ferdjaoui, N. (2014).Shared decision-making in medical encounters regarding breast cancer treatment: the contribution of methodological triangulation.European Journal of Cancer Care, 24(4), 461-472. doi:10.1111/ecc.12214

Hill, C., \& Burrows, G. (2017). New voices: The usefulness of a narrative approach to social work research. Qualitative Social Work: Research and Practice, 16(2), 273-288. doi:10.1177/1473325017689966

Hoffman, D. D., Singh, M., \& Prakash, C. (2015). The Interface Theory of Perception Psychonomic.Bulletin \& Review, 22(6), 1480-1506. doi:10.3758/s13423-015-0890-8

ITU (2017).Intellectual Property Rights (IPRs), International Telecommunication Union, Retrieved May 22, 2017, from http://www.itu.int/en/ITU-T/ipr/Pages/default.aspx.

Komatsu, A., Takagi, D., \& Takemura, T. (2013).Human aspects of information security.Information Management \& Computer Security, 21(1), 5-15. doi:10.1108/09685221311314383

Narain, S. A., Gupta, M. P., \&Ojha, A. (2014). Identifying factors of "organizational information security management. Journal of Enterprise Information Management, 27(5), 667-644.doi:10.1108/jeim-07-20130052

Neba, A. (2013). IPR systems and technology transfer at research institutions in southern Africa. Regional and Thematic Papers on Research Management 2009-2013

Nwokocha, U. (2012 ). Nigerian Intellectual Property: Overview Of Developments \&Practice. Journal of Intellectual Property [NJIP], 101-116. http://www.nials-nigeria.org/journals/Uche\%20NwokochaNJIP\%202.pdf

Oladimeji, T. T., \& Foltyn, G. B. (2018). ICT and Its Impact on National Development In Nigeria: An Overview. Research \& Reviews: Journal of Engineering and Technology, 7(1), 1-10.

Olise, F. P. (2010). Information and Communication Technologies (ICTs) and Sustainable Development in Africa: Mainstreaming the Millennium Development Goals (MDGs) into Nigeria's Development Agenda.Journal of Social Sciences, 24(3), 155-167. 
Perez, R. G., Branch, R., \& Kuofie, M. (2014).EOFISI Model as a Predictive Tool to Favor Smaller Gaps on the Information Security Implementations.Journal of Information Technology and Economic Development, 5(1), $1-20$.

Piquero, N. L. (2005). Causes and prevention of intellectual property crime.Trends in Organized Crime, 4(1), 4061.

Reid, R. (2012). What to Do When Attacked By Pirates. Wall Street Journal.Retrieved from http://www.wsj.com/articles/SB10001424052702303552104577438212250619458.

Sargolzaei, E., \& Fateme , F. (2017). Examining software Intellectual Property rights. (IJACSA) International Journal of Advanced Computer Science and Applications, 8(11), 594-600.

Scarnato, J. M. (2017). The value of digital video data for qualitative social work research: A narrative review. Qualitative Social Work: Research and Practice, doi:10.1177/1473325017735885

Stallings, W., \& Brown, L. (2012). Computer security: Principles and practice (2nd ed.).Upper Saddle River, NJ: Prentice Hall.

Stewart, G., \& Lacey, D. (2012),"Death by a thousand facts", Information Management \& Computer Security, 20(1), 29-38.doi:10.1108/09685221211219182

Tade, O., \& Akinleye, B. (2012) . "We are Promoters not Pirates": A Qualitative Analysis of Artistes and Pirates on Music Piracy in Nigeria. International Journal of Cyber Criminology, 6(2). Retrieved from: http://www.cybercrimejournal.com/ Tade \& Akenliye2012julyijcc.pdf

Taylor, R. G., \& Robinson, S. L. (2015). An information system security breach at First Freedom Credit Union 1: what goes in must come out. Journal of the International Academy for Case Studies, 21(1), 131-138.

Toyo, O. D., \& Ejedafiru, F. E. (2016).Utilization of Information and Communication Technologies (ICTs) for Sustainable EconomicDevelopment in Nigerian. International Journal of Ergonomics and Human Factors, 12(2), 22-34.

Dr. Felix. C. Aguboshim holds a doctorate degree in information technology in 2018 from Walden University Minneapolis, MN55401, USA. In his lower degrees, he majored in systems science, computer science and engineering, and information technology. He became an associate Member of the Institute of Statisticians London in 1979, a Member of Nigerian Computer Society (MNCS) in 2004 and Computer Professionals (Registration Council of Nigeria) (MCPN) in 2006. He became a Senior Lecturer and the Head of Department of Computer Science, Federal Polytechnic, Oko, Nigeria in 1995. He is presently a Principal Lecturer in 2006.

Irene. N. Ezeasomba holds a Masters degree in Computer Science in 2006 from Nnamdi Azikiwe University, Awka Nigeria. In her Bachelor's degrees, she majored in computer science and engineering. She became a Member of Nigerian Computer Society (MNCS) in 2006 and Computer Professionals (Registration Council of Nigeria) (MCPN) in 2008. She became a Senior Lecturer in the Department of Computer Science in 2011, and a Principal Lecturer in 2014. She is presently the Head of the Department of Computer Science, Federal Polytechnic, Oko. Nigeria and a Fellow in the Institute of Corporate Administration of Nigeria in 2012. 